\title{
Effects of Hypophysectomy and Thyroidectomy on Salt Balance in the Plethodontid Salamanders, Desmognathus fuscus and Desmognathus monticola
}

\author{
Patricia Stocking Brown ${ }^{1}$, Stephen C. Brown ${ }^{2}$, and B.E. Frye ${ }^{3}$ \\ ${ }^{1}$ Department of Biology, Siena College, Loudonville, New York 12211, USA \\ ${ }^{2}$ Department of Biological Sciences, S.U.N.Y., Albany, New York 12222, USA \\ ${ }^{3}$ Department of Biology, University of Michigan, Ann Arbor, Michigan 48104, USA
}

Accepted May 22, 1979

Summary. Hypophysectomy significantly reduced serum sodium levels in Desmognathus fuscus and D. monticola. Prolactin, corticosterone or aldosterone replacement failed to restore serum sodium to control levels. Hypophysectomy also led to decreases in in vitro integumental potential difference and shortcircuit current, which were not restored to control levels by prolactin or corticosterone. Thyroidectomy significantly reduced the level of serum sodium in D. monticola, but it increased in vitro potential difference and short-circuit current. Thyroxine treatment of either hypophysectomized or thyroidectomized D. monticola completely restored serum sodium, potential difference and short-circuit current to control levels.

\section{Introduction}

There is general agreement that the pituitary gland is important in regulating mineral balance in amphibians since hypophysectomy results in lowered serum sodium levels in both anurans and urodeles (Middler et al., 1969; Crim, 1972; Brown and Brown, 1973; Pang and Sawyer, 1974; Oguro and Uchiyama, 1975; Wittouck, 1975). However, the identity of the specific pituitary hormone(s) involved in such regulation remains obscure. For example, although several workers have found evidence that prolactin may play an important role in maintaining salt balance (Wittouck, 1972, 1975; Pang and Sawyer, 1974; Gallagher, 1974), other investigators have found prolactin treatment to be either without effect (Brown and Brown, 1973; Platt and Christopher, 1977) or to lower salt levels even further (Crim, 1972). Similarly, adrenocorticotrophin (ACTH) or adrenal steroids have been shown to be effective in maintaining serum sodium in some amphibians (Chester Jones, 1957; Myers et al., 1961; Jorgensen and Larsen, 1963; Middler et al., 1969) but not others (Crim, 1972). A third pituitary hormone, thyrotrophin (TSH), acting via thyroid hormones, has received some attention as a salt-controlling factor in amphibians. However, initial reports of its effectiveness in regulating in vitro sodium transport in anuran tissues (e.g., Green and Matty, 1963; Matty and Green, 1964; Marusic and Toretti, 1964) have not been substantiated (e.g., Taylor and Barker, 1964, 1967; Marusic et al., 1966)

In this paper we report the results of an investigation on the hormonal control of salt balance in two species of plethodontid salamanders.

\section{Materials and Methods}

Animals

Desmognathus monticola (3.75-4.62 g) and Desmognathus fuscus $(1.48-2.32 \mathrm{~g})$ were collected from streams near the Mountain Lake Biological Station, Blacksburg, Virginia, and all experiments were carried out at the Station. The animals were maintained in finger bowls on wet paper towels (changed daily) at room temperature. They experienced natural day lengths (July and August) although the light intensity was low. Experiments were initiated within a few days of collection and the animals were not fed during the course of the study.

\section{Surgical Procedures}

Prior to surgery, all animals were anesthetized by an intraperitoneal injection of $0.1 \mathrm{ml}$ of $1.0 \% \mathrm{MS}-222$ (tricaine methane sulfonate, Sigma). For hypophysectomy the pituitary was exposed by drilling a hole through the parasphenoid bone in the roof of the mouth, and the gland removed with fine forceps. Sham hypophysectomy consisted of drilling the hole, but leaving the pituitary intact. For thyroidectomy an incision was made through the skin on both sides of the neck and the underlying muscle cut to expose the carotid artery and thyroid gland. The thyroid was then removed with fine forceps. Sham thyroidectomy consisted of exposing the gland as described above, but leaving it in place. 

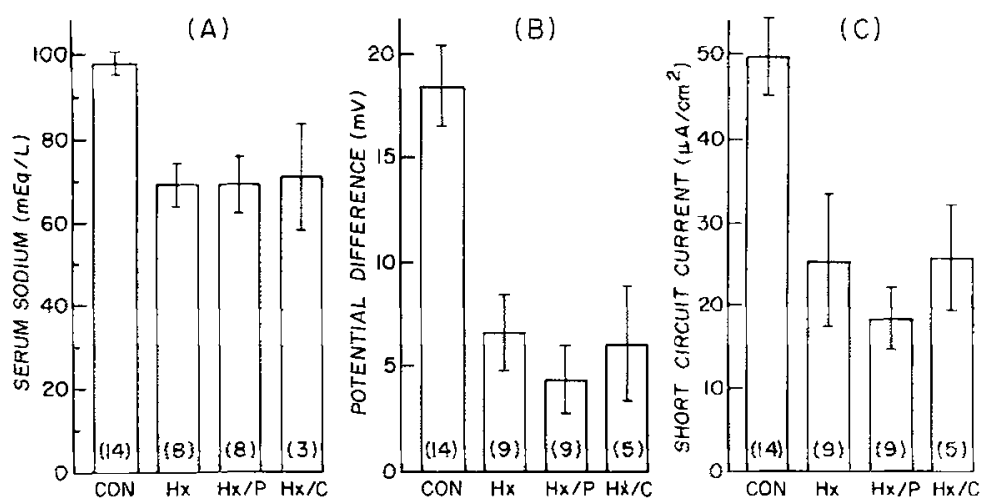

Fig. 1A-C. Effects of hypophysectomy $(\mathrm{Hx})$ and replacement prolactin $(\mathrm{Hx} / \mathrm{P})$ and corticosterone $(\mathrm{Hx} / \mathrm{C})$ treatment, in Desmognathus fuscus. A Serum sodium.

B In vitro integumental potential difference. $C$ In vitro integumental short-circuit current. Means $\pm \mathrm{SE}$; numbers in parentheses $=$ number of observations
Blood Sodium Measurement

Blood samples were collected in $200 \mu \mathrm{l}$ capillary tubes following aortic transection. The capillaries were flame-sealed, centrifuged and stored at $4^{\circ} \mathrm{C}$ until analyzed. For sodium determinations, serum samples were diluted with an appropriate amount of glass-distilled water. Flame photometry was carried out using a Coleman Ir. II spectrophotometer with flame attachment, and the results compared to a standard curve made from solutions of known sodium concentration.

Integumental Potential Difference, Short-Circuit Current and Osmotic Permeability

In vitro preparations of ventral belly skin were made according to procedures previously described (Brown and Brown, 1973). Potential difference and short-circuit current measurements were made with amphibian Ringer's on both sides of the membrane, employing standard methods (Ussing and Zerahn, 1951; Brown and Brown, 1973).

Experimental Design

Following surgery in each experiment, a recovery period of 3 days was allowed to elapse before replacement injections were begun.

Experiment 1. D. fuscus were divided into groups and treated as follows: (A) Sham hypophysectomy - injected with $5 \mu l$ saline $(0.7 \% \mathrm{NaCl})$ each day; (B) Hypophysectomy - injected with $5 \mu 1$ saline/day; (C) Hypophysectomy - injected with $10 \mu \mathrm{g}$ prolactin $(\mathrm{NIH} \mathrm{B}-2,19.9 \mathrm{lU} / \mathrm{mg})$ in $10 \mu \mathrm{l}$ saline/day; and (D) Hypophysectomy - injected with $10 \mu \mathrm{g}$ corticosterone suspended in $10 \mu 1$ saline/ day. At the end of 10 days treatment, serum sodium, in vitro potential difference and short-circuit current were measured.

Experiment II. D. monticola were divided into groups and treated as follows: (A) Sham hypophysectomy - injected with $5 \mu$ l solvent (propylene glycoly/day; (B) Hypophysectomy - injected with $5 \mu l$ solvent/day; and (C) Hypophysectomy - injected with $10 \mu \mathrm{g}$ aldosterone in propylene glycol/day. At the end of 14 days treatment, serum sodium was measured.

Experiment III. D. monticola were divided into groups and treated as follows: (A) Sham thyroidectomy - injected with $5 \mu \mathrm{l}$ saline/day; (B) Thyroidectomy - injected with $5 \mu 1$ saline/day; (C) Thyroidectomy - injected with $0.2 \mu \mathrm{g}$ thyroxine $\left(\mathrm{T}_{4}\right)$ in $5 \mu \mathrm{l}$ saline/day; and (D) Hypophysectomy - injected with $0.2 \mu \mathrm{g}$ thyroxine/day. At the end of 9 days treatment, serum sodium, in vitro potential difference and short-circuit current were measured.

\section{Results}

Experiment I. Removal of the pituitary from Desmognathus fuscus (Fig. 1A) reduced the level of serum sodium (by $30 \%$ compared to sham; $P<0.001$ ) as well as in vitro integumental potential difference (Fig. 1B; $P<0.001$ ) and short-circuit current (Fig. 1C; $P<0.01$ ). Neither prolactin nor corticosterone treatment of hypophysectomized animals restored serum sodium, in vitro integumental potential difference or short-circuit current to sham values (Figs. 1 A-C).

Experiment II. Removal of the pituitary from Desmognathus monticola (Fig. 2) reduced the level of serum sodium (by $18 \%$ compared to sham; $P<0.05$ ). Aldosterone-treated, hypophysectomized animals had even lower serum sodium levels (a reduction of $36 \%$ compared to sham; $P<0.001$ ). The difference between hypophysectomy and hypophysectomy + aldosterone was not statistically significant.

Experiment III. Removal of the thyroid from $D$. monticola (Fig. 3A) also significantly reduced the level of serum sodium (by $8 \%$ compared to sham;

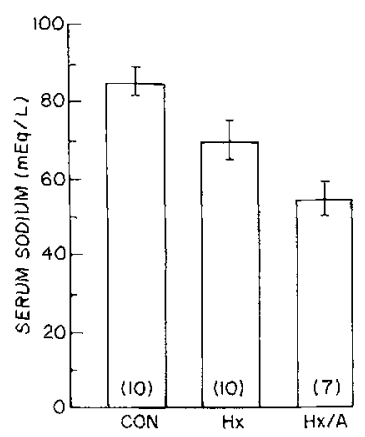

Fig. 2. Effects of hypophysectomy $(\mathrm{Hx})$ and replacement aldosterone $(\mathrm{Hx} / \mathrm{A})$ treatment on serum sodium, in Desmognathus monticola. Means $\pm \mathrm{SE}$. ; numbers in parentheses $=$ number of observations 

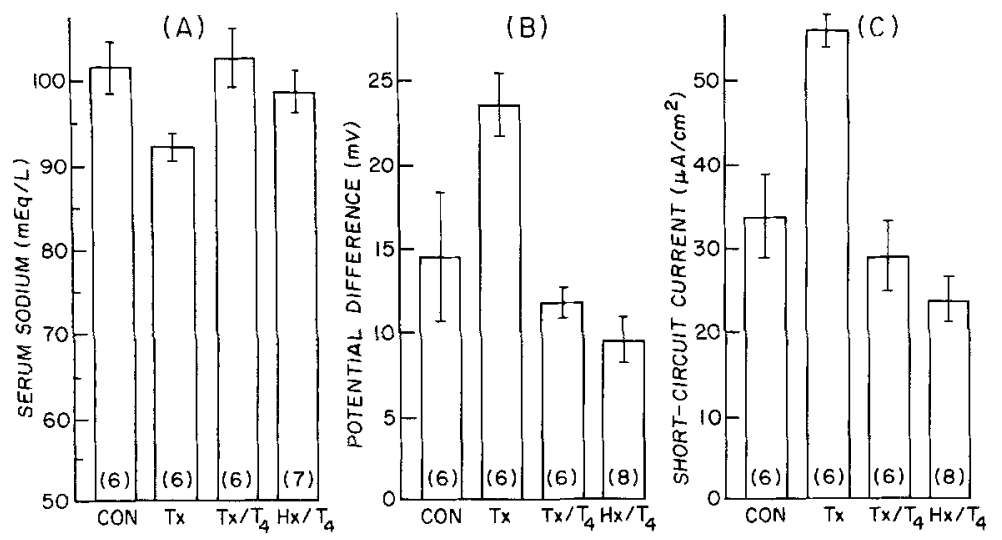

Fig. 3A-C. Effects of thyroxine treatment of thyroidectomized $\left(\mathrm{Tx} / \mathrm{T}_{4}\right)$ and hypophysectomized $\left(\mathrm{Hx} / \mathrm{T}_{4}\right)$ Desmognathus monticola. A Serum sodium.

B In vitro integumental potential difference. C In vitro integumental short-circuit current. Means $\pm \mathrm{SE}$; number in parentheses $=$ number of observations

$P<0.025$ ). Most interesting was the finding that thyroxine treatment restored serum sodium levels to normal in both thyroidectomized and hypophysectomized animals. In contrast to the effect of hypophysectomy (Fig. 1), thyroidectomy increased in vitro integumental short-circuit current and potential difference (Fig. 3B and C; $P<0.005$ between sham and thyroidectomy, for both). As with serum sodium, thyroxine treatment of both thyroidectomized and hypophysectomized animals restored integumental shortcircuit current and potential difference to control values (Fig. $3 \mathrm{~B}$ and $\mathrm{C}$ ).

\section{Discussion}

In the present series of experiments, hypophysectomy decreased the levels of serum sodium by $18 \%$ of sham values in Desmognathus monticola and by $30 \%$ in D. fuscus. The decrease seen in D. fuscus is comparable to those reported by Middler et al. (1969) for Bufo marinus (25-31\%), by Wittouck (1975) for larval Ambystoma mexicanum (23-29\%), and by Oguro and Uchiyama (1975) for Cynops pyrrhogaster (29\%) and Hynobius nigrescens (23\%). The somewhat smaller effect seen in D. monticola is comparable to those found by Gallagher (1974) and Pang and Sawyer (1974) for Necturus maculosus (19\% and 8-18\%, respectively), by Brown and Brown (1973) for Notophthalmus viridescens $(17 \%)$, and by Crim (1972) for Taricha torosa $(8-11 \%)$ and Rana pipiens $(9-13 \%)$. The comparatively large magnitude of the decrease in serum sodium, following hypophysectomy, in the Desmognathus species clearly indicates the importance of pituitary hormones in the regulation of sodium balance in these two semi-aquatic urodeles.

Prolactin clearly did not correct for the effects of hypophysectomy on serum sodium in D. fuscus. Previously, prolactin has been reported to maintain normal serum sodium levels in hypophysectomized larval Ambystoma tigrinum (Wittouck, 1975) and in one out of three experiments on Necturus maculosus (Pang and Sawyer, 1974). Serum sodium levels intermediate between sham and hypophysectomized animals were maintained by prolactin treatment in the remaining two experiments of Pang and Sawyer (1974) and also in Gallagher's (1974) experiment on Necturus. However, prolactin treatment failed to significantly raise serum levels in hypophysectomized Notophthalmus viridescens (Brown and Brown, 1973) or intact Ambystoma tigrinum (Platt and Christopher, 1977), and was found to lower sodium still further in hypophysectomized Taricha torosa and Rana pipiens (Crim, 1972).

Pang and Sawyer (1974) propose that such variable results may be due to failure to start prolactin treatment immediately after surgery. Alternatively, Crim (1972) suggests that diurnal variation in hormone effectiveness may at least partially explain the disparity in results. To us, a more likely explanation will be found along the lines of suggestions by Bern (1975) and Platt and Christopher (1977) that prolactin may have unique osmoregulatory influence in juvenile, typically aquatic stages of amphibians. We would amend this general hypothesis by specifically suggesting that while prolactin is probably involved in some aspect of osmoregulation in virtually all amphibians, it is only sodium-retaining in functionally "juvenile" stages (i.e., larvae or neotenic forms).

In our experiments, hypophysectomy also resulted in a decrease in in vitro integumental short-circuit current and potential difference. This suggests that a decrease in sodium uptake may at least partially account for the observed decrease in serum sodium. Although Myers et al. (1961) also found a decrease in skin short-circuit current and potential difference following hypophysectomy in Rana pipiens, Lodi et al. (1978) report that hypophysectomy of Triturus cristatus led to increased in vitro integumental shortcircuit current.

Prolactin treatment of hypophysectomized D. fuscus failed to restore short-circuit current or potential 
difference to sham values. This is consistent with data from other experiments which show that in adult animals, prolactin either has no effect on integumental short-circuit current (Harlow, 1977) or actually lowers it (Brown and Brown, 1973; Lodi et al., 1978).

There are a number of studies on adult amphibians which indicate that $\mathrm{ACTH}$ or adrenal hormones are necessary to maintain serum sodium (Chester Jones, 1957; Myers et al., 1961; Jorgensen and Larsen, 1963; Middler et al., 1969). However, in our experiments, neither aldosterone nor corticosterone significantly raised serum sodium, and aldosterone may actually have lowered it further. Middler et al. (1969) and Crim (1972) likewise found no effect of aldosterone replacement in maintaining serum sodium in hypophysectomized toads and newts, respectively.

An interesting outcome of these experiments is the demonstration that thyroidectomy of $D$. monticola results in a decrease in serum sodium and an increase in short-circuit current, while thyroxine replacement in either hypophysectomized or thyroidectomized animals results in normal values. This indicates that thyroid hormones are very important, either directly or indirectly, in the regulation of salt balance in this species. Although few, if any, other studies have determined serum sodium in amphibians after thyroidectomy, there are a few pieces of indirect evidence suggesting that thyroid hormones may have a role in salt regulation. For example, thyroxine treatment of intact Notophtalmus viridescens resulted in decreased levels of serum sodium (Brown and Brown, 1973). In addition, Lodi et al. (1978) found that thyroxine treatment of intact Triturus cristatus increased integumental short-circuit current in winter, but not summer, animals. They also found that thyroidectomized newts showed increased skin short-circuit current, such as was observed in our experiments with D. monticola.

The proximate cause of the hyponatremia observed in thyroidectomized salamanders is not presently known, but it may well be due to increased urinary sodium loss since the short-circuit current data indicate that sodium uptake through the skin is increased, not decreased, by thyroidectomy. In this regard, certain data from studies on thyroid hormone actions in mammals may prove to be relevant. For example, Fregly and Taylor (1974) have shown that hypothyroid rats have an increased urinary sodium loss, a decreased urinary concentrating capacity, and an increased sodium and water intake. These authors suggest that hypothyroidism alters both the secretion of, and sensitivity to, aldosterone and antidiuretic hormone. On the other hand, the proposal of IsmailBeigi and Edelman $(1970,1971)$ that thyroid hormone action in mammals is primarily related to sodium transport may also be applicable to amphibian salttransporting systems. It is clear that future studies on amphibians must attempt to determine whether thyroid hormone acts directly, by regulating membrane salt-transport mechanisms, or indirectly, by influencing the secretion of, and/or sensitivity to, other hormones, or both.

We acknowledge, with thanks, M. Murphy and E. Frye for help in collecting the animals. This work was carried out at the University of Virginia Mountain Lake Biological Station, and we express our appreciation to the station director, Dr. James Riopel.

\section{References}

Bern, H.A.: On two possible primary activities of prolactin: osmoregulatory and developmental. Verh. Dtsch. Zool. Ges. 1975, 40-46 (1975)

Brown, P.S., Brown, S.C.: Prolactin and thyroid hormone interactions in salt and water balance in the newt, Notophthalmus viridescens. Gen. Comp. Endocrinol. 20, 456-466 (1973)

Chester Jones, I.: The adrenal cortex. London, New York: Cambridge University Press 1957

Crim, J.W.: Studies on the possible regulation of plasma sodium by prolactin in Amphibia. Comp. Biochem. Physiol. 43A, 349-357 (1972)

Fregly, M.J., Taylor, R.E.: Effect of hypothyroidism on water and sodium exchange in rats. In: Thirst, Proceedings of the First International Symposinm on the Regulation of Body Water. Wagner, M.J. (ed.), pp. 139-175. London: Pergamon Press 1974

Gallagher, J.A.: Hormonal control of electrolyte metabolism in the mudpuppy, Necturus maculosus. Masters Thesis, University of Wisconsin-Milwaukee (1974)

Harlow, H.J.: Effects of prolactin on cutaneous water and sodium transport in newts. Copeia 1977, 745-746 (1977)

Green, K., Matty, A.J.: Action of thyroxine on active transport in isolated membranes of Bufo bufo. Gen. Comp. Endocrinol. 3, 244-252 (1963)

Ismail-Beigi, F., Edelman, I.S.: The mechanism of thyroid calorigenesis: Role of active sodium transport. Proc.Natl.Acad. Sci. USA 67, 1071-1077 (1970)

Ismail-Beigi, F., Edelman, I.S.: The mechanism of the calorigenic action of thyroid hormone: Stimulation of $\mathrm{Na}^{+}+\mathrm{K}^{+}$-activated adenosinetriphosphatase activity. J. Gen. Physiol. 57, 710-722 (1971)

Jorgensen, C.B., Larsen, L.O.: Effect of corticotrophin and growth hormone on survival in hypophysectomized toads. Proc. Soc. Exp. Biol. 113, 94-96 (1963)

Lodi, G., Biciotti, M., Sacerdote, M.: Osmoregulatory activity of prolactin in the skin of the crested newt. Gen. Comp. Endocrinol. 36, 7-15 (1978)

Marusic, E., Martinez, R., Toretti, J.: Unresponsiveness of the adult toad to thyroxine administration. Proc. Soc. Exp. Biol. Med. 122, 164-167 (1966)

Marusic, E., Toretti, J.: Synergistic action of vasopressin and thyroxine on water transfer in the isolated toad bladder. Nature 202, 1118-1119 (1964)

Matty, A.J., Green, K.: Effect of thyroxine on ion movement in isolated toad bladder. Gen. Comp. Endocrinol. 4, 331-338 (1964)

Middler, S.A., Kleeman, C.R., Edwards, E., Brody, D.: Effect of adenohypophysectomy on salt and water metabolism in the toad Bufo marinus, with studies on hormonal replacement. Gen. Comp. Endocrinol. 12, 290-304 (1969) 
Myers, R.M., Bishop, W.R., Scheer, B.T.: Anterior pituitary control of active sodium transport across frog skin. Am. J. Physiol. 200, 444-450 (1961)

Oguro, C., Uchiyama, M.: Control of serum calcium concentration by parathyroid gland in two species of urodele amphibians. Gen. Comp. Endocrinol. 27, 531-535 (1975)

Pang, P.K., Sawyer, W.H. : Effects of prolactin on hypophysectomized mudpuppies, Necturus maculosus. Am. J. Physiol. 226, 458-462 (1974)

Platt, J.E., Christopher, M.A.: Effects of prolactin on the water and sodium content of larval tissues from neotenic and metamorphosing Ambystoma tigrinum. Gen. Comp. Endocrinol. 31, 243-248 (1977)

Taylor, R.E., Barker, S.B.: Thyroxine and activity of amphibian skin and bladder. Fed. Proc. 23, 107 (1964)
Taylor, R.E., Barker, S.B.: Absence of an in vitro thyroxine effect on oxygen consumption and sodium or water transport by anuran skin and bladder. Gen. Comp. Endocrinol. 9, 129-134 (1967)

Ussing, H.H., Zerahn, K. : Active transport of sodium as the source of electric current in the short-circuited isolated frog skin. Acta Physiol. Scand. 23, 110-127 (1951)

Wittouck, P.J. : Modification de la retention du sodium chez Ambystoma mexicanum (axolotl), intact et hypophysectomisé sous l'effet de la prolactine. Arch. Int. Biochem. Physiol. 80, 825-827 (1972)

Wittouck, P.J.: Influence de la composition saline du milieu sur la concentration ionique du serum chez l'Axolotl, intact et hypophysectomisé sous l'effet de la prolactine. Gen. Comp. Endocrinol. 27, 169-178 (1975) 